\title{
The Impact of Qualitative Visual Vision Trainings on the Concentration of Attention and Precision of Counter-attack for Boxing Players
}

\section{Dr/ Al-Sayed Ali Abdallah Shabeb}

Lecturer in the Department of Sports Training and Movement Science - Faculty of Physical Education - Assiut University

\section{Introduction and Problem of the Research:}

The pursuit of higher levels in many sports has become a topic that attracts the attention of specialists in the field of sports, which leads to overcoming most of the training problems in order to raise the level of sports and achieve the digital achievement for athletes.

A sport training is based on scientific foundations which are essentially subject to the principles and laws of the natural and human sciences, because it is considered the essential element for the success of any sports activity because it has an effective and important role in preparing the players physically, skillfully, schematically and psychologically to reach them to the required level. In the view of Mufti Ibrahim Hammad (2010), the science of sports training is to find modern methods which must be taken into account in each position of training and competition and must be legalized in order to achieve the best possible level of performance $(13: 9,10)$.

Isabel Walker (2001) has referred that sports scientists and trainers are constantly looking for modern means and programs aimed at improving athletic performance and gaining a competitive edge. Visual training is one of the most well-known techniques in the field of sports as it is repetitive series of eyes exercises to improve basic visual abilities which are important for athletes in all competitive sports. (20: 203) (21: 2) (25)

Visual training is one of the branches of visualism (measurement of sight), a branch concerned with the perception and sight and also the assessment and improvement of visual performance, as well as the identification of the most appropriate visual instruments for the nature of sports activity. (18: 127) . In the view of the researcher, the visual vision is a set of neuro-muscular skills that can be learned, trained and developed and include many components such as visual concentration.

Concentration of attention is one of the most important psychological skills for athletes as it is the basis for the success of learning, training or competition in its various forms. Attention distraction or lack of concentration negatively affects the performance of many athletes and their low performance in competition is due to the lack of concentration of the stimuli associated with something to achieve effective performance

$(2: 286)(Y V) \cdot(Y T): !)$ 
Sobhi Hassanein (2001) has referred to the importance of precision for many sports activities such as Fencing, shooting, karate, boxing and group games. The precision component is not only important in sports fields, but also extends to public life (7: 229) (11: 358).

The punch, which is characterized by speed and lack of precision, is often not successful which shows the importance of precision to the boxer, especially in the matches during the game. The researcher sees that the precision in boxing is the ability of the boxer to continue opening the gaps for the competitor and punching towards him, whether fixed or moving, and the ability to follow this goal is very difficult as it needs to visual concentration with a high degree and that's for discovering the gaps of the competitor and hitting him as well as following the referee's signs and the trainer's instructions, which increase the need to improve the boxer's good vision.

Visual exercises are considered important subjects that have not received much attention from researchers in the field of sports in general and boxing in particular, as the sense of sight has a great importance to the boxer in scoring points and increasing his ability of concentration attention. The researcher has noted, by attending many tournaments and also training the team of the college and the university, that there are some boxers during the training have had a high level of performance and achieved high results in the experimental games, until decline the performance suddenly and achieve unexpected results during official tournaments.

The results of the matches are the most important indicators that reflect the level of achievement of athletes to reach the high levels, where boxing is characterized by rapid sudden change during the game and punching or avoidance in the attack and defense, which require rapid or precise responses which need for a high level of attention while hitting punches (93: 8)

Therefore, the researcher has tried to explain the phenomenon mentioned above and discovered that it may be because of the lack of concentration of the boxer's attention and dispersion between different stimuli, including the movements of the competitor, change his sudden direction, referee's signs, comments of the coach and the fan's warnings and thus affect the performance of boxer.

Mohamed Abdul Aziz "(2004) has indicated that these visual stimuli, which are picked up by the eye of the player, are located in the vicinity of his sight during and after the initiation of his motor performance, both technically and physically

(7: 12).

All this require the boxer so-called visual concentration, namely to focus on the goal of the opponent, and to understand the depth of any distance between 
him and the competitor and that is determined by the use of any type of punches. Through this the boxer enables to understand the type of precision required. Is it stable or moving?

All these variables, if available in the boxing player, help him to increase his ability to record many groups of punching correctly and quickly during the game. (24)

The researcher also sees that the speed of performance, the surprise of the opponent to attack and the speed of moving to the different positions of the different punching and linking the defense to the precision of counter-attack in a lightning faster than the opponent are the most important elements that help the boxer to win games. Boxing is one of the most competitive sports in world championships and Olympic Games and has many major physical and motor requirements and abilities, which are clearly visible in offensive and defensive movements due to changing punching positions during the match.

Achieving the goal and score points not to harm the opponent has become required in the sport of boxing modern, especially under the arbitration by computer

Many of the advanced countries in boxing such as Cuba, America, Russia, Romania, Germany and Bulgaria have realized that the importance of rapid adjustment in training methods has become increasingly important in modern boxing, especially with computer arbitration, to keep pace with this development, which is reflected positively on the speed and precision of performance in hitting punches in the areas authorized punching $(4: 112,113)$. The law states that the punch must be strong and fast, which requires a concentration of attention with precision in the hitting punches to reach the authorized place to punch in order to score a point. Thus, it is clear that the boxer must be well trained to hit sets of either offensive or defensive punches quickly and accurately and have the ability to direct the punches to the target of the opponent accurately, quickly and in appropriate time.

The study of "Abernethy Wood" (2001) (17), "Elizabeth S3.Bresson" (2003) (19), "Thomas.et al (2005) (23), Poulter. et al "(2005) (22), Jehan Fouad, Iman Abdullah (2005) (5), and Nadia El Sawy, Zainab Hathout (2008) (14), Huda Hassan (2008) (16), Majid Mustafa, Abdul Mohsen Zakaria (2006), (10), Hatem Fathallah (2011), (6) and Nahla Jamal (2014), (15), has showed that The need of using the visual trainings and the positive effect in improving attention concentration and precision and speed of the performance of the players. Ashraf Mustafa`s study (2008) (3) has recommended the importance of the use of qualitative exercises to improve some of the variables of sensory kinetic perception and precision of counter hitting offensive punches for the first degree boxers and hence came the idea of this research, which called for the 
use of visual vision training to improve both the concentration of attention and the precision of the counter-attack for the boxers of the first degree, because they contain trainings of visual tracking, visual focus, external awareness, depth awareness, quick reaction, harmony between the eye, hand and body, visual precision.

\section{Aims of the Research:}

The aim of the research is to design a training program using visual vision trainings and studying their effects on:

1- Concentration of the attention for the boxing players (sample of the research)

2-The precision of the counter attack for the boxing players (sample of the research).

\section{Research Hypotheses:}

1- There are statistically significant differences between the averages of the pre-measurement and the post measurement in the concentration of attention for the research sample in favor of the post measurement.

2-There are statistically significant differences between the averages of the pre-measurement and the post measurement in the precision of the counter attack for the sample research in favor of the post measurement.

\section{Procedures of the Research:}

\section{Research Methodology:}

The researcher used the experimental approach using "experimental design of one group by pre and post measurements" for its relevance to the nature and aims of the research.

\section{Research Community :-}

The research community represents the first class boxers registered in the Egyptian Federation of Boxing for the sports season 2016/2017 "Assiut" and they are (16) boxers.

\section{Sample of the Research:}

The basic research sample was chosen in a deliberate manner from the first class boxers registered in the Egyptian Federation of Boxing "Assiut Branch", aged 19-20 years.

Table (1)the research sample report and the clubs

\begin{tabular}{c|c|c|c}
\hline \hline Sports institutions & Basic sample & Exploratory sample & weight \\
\hline \hline Young Muslims Association & $r$ & $r$ & 56 \\
\hline Nasser Youth Center & $r$ & $r$ & $60-64$ \\
\hline Military establishment & $\varepsilon$ & $\varepsilon$ & $69-69-75-75$ \\
\hline Total & $\wedge$ & $\wedge$ & - \\
\hline \hline
\end{tabular}


Table (1) shows that the number of basic sample boxers is (8) boxers, and the number of exploratory sample is (8) boxers in different weights (56-60 - 64 - 69 - 75) and (8) boxers for the exploratory sample. Table (1) shows a description of the individuals of the sample research.

\section{Homogeneity among the individuals of the research sample:}

The researcher has conducted the measurements of homogeneity in order to find the torsion coefficient for the members of the basic research sample before applying the proposed training program to indicate the homogeneity of the members of the basic research sample to ensure moderation in the basic research variables that may affect the results of the research and the torsion coefficients as shown in Table (2)

Table (2)

\begin{tabular}{|c|c|c|c|c|c|}
\hline \multirow[t]{2}{*}{ Report } & \multirow[t]{2}{*}{ Measurements } & \multirow{2}{*}{$\begin{array}{c}\text { Measurement } \\
\text { unit }\end{array}$} & \multicolumn{3}{|c|}{$\begin{array}{c}\text { Statistical Significance of } \\
\text { Characterization }\end{array}$} \\
\hline & & & $\begin{array}{c}\text { Arithmetic } \\
\text { average }\end{array}$ & $\begin{array}{l}\text { Standard } \\
\text { deviation }\end{array}$ & $\begin{array}{c}\text { Torsion } \\
\text { coefficient }\end{array}$ \\
\hline \multirow{4}{*}{$\begin{array}{l}\frac{u}{n} \\
\qquad \\
\infty\end{array}$} & age & Year / month & 19,63 & .,52 &.,- 64 \\
\hline & length & $\mathrm{M} / \mathrm{cm}$ & 171 & 2,14 & 0,58 \\
\hline & weight & $\mathrm{Kg} / \mathrm{g}$ & 64,88 & 7,61 & 0,27 \\
\hline & training age & Year / month & 8,88 & 2,80 & 0,95 \\
\hline
\end{tabular}

Table (2) shows that the values of the torsion coefficients in the variables in

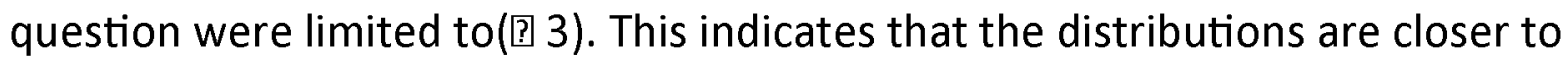
moderation in the (age, height, weight, training age) variables, indicating the homogeneity of the sample.

\section{* Data collection tools:}

The researcher has identified the tools and devices used on the research sample through the researcher's reading the scientific references and previous Arab and foreign studies specialized in sports training in general and in training .boxing in particular

\section{*Used equipment:}

-Expert consultation questionnaire on the identification of axes and time periods for the proposed training program. Attachment (6)

-Expert consultation questionnaire on determining the most appropriate exercises for visual vision exercises. Attachment (7)

-Attention concentration test. Attachment (4/1)

-Registration form to measure concentration of attention (designed by the researcher). Attachment (4/2)

-The precision of counter-attack test . Attachment (5/1)

-Recording form of the measurement counter-attack (designed by the researcher). Attachment (5/2) 
* Used devices:

-Medical balance to measure the weight in kilograms

-Resistometer to measure the length (centimeter)

-Stopwatch for measuring time.

-Cones, colored ribbons. - Punching bag for training. - Tennis Balls. - Legal

-gloves - Red and white banners. - Colored circles of cardboard.

\section{Scientific transactions used in the research:}

The researcher has conducted the scientific transactions on a sample of the research community (exploratory sample), which did not participate in the basic experiment, and it has reached ( 8 ) boxers from the first class. The concentration of attention and precision of counter-attack were measured.

\section{A- Validity:}

The researcher used the validity of differentiation by conducting the measurements on a distinctive sample who are boxers of the military establishment composed of 4 boxers, who are distinctive by a high level of physical and athletic performance, the training age, their access to tournaments.. The non-distinctive group are boxers in the Young Muslim Club and Naser Youth Center who are (4) boxers. This measurement was carried out from $2 / 3 / 2017$ to $3 / 3 / 2017$. The researcher has calculated the differences between the two distinctive and non-distinctive groups to verify the validity of the visual variable and the "skilled physical" variable. Table (3) shows this.

\section{Table (3)}

Significance of differences between the distinctive group and the nondistinctive group in the concentration of attention and the precision of counter-attack (under study) $\mathrm{N}=\mathrm{N}=2$ (4)

\begin{tabular}{c|c|c|c|c|c|c|c}
\hline \hline \multirow{2}{*}{ measurements } & $\begin{array}{c}\text { Measurement } \\
\text { unit }\end{array}$ & \multicolumn{2}{|c|}{$\begin{array}{c}\text { Distinctive } \\
\text { group }\end{array}$} & \multicolumn{2}{|c|}{$\begin{array}{c}\text { Non- } \\
\text { distinctive } \\
\text { group }\end{array}$} & $\begin{array}{c}\text { T } \\
\text { value }\end{array}$ & Significance level \\
\cline { 2 - 6 } & & $\mathbf{S}$ & $\mathbf{A} \pm$ & $\mathbf{S}$ & $\mathbf{A} \pm$ & & \\
\hline \hline $\begin{array}{c}\text { concentratio } \\
\text { n of } \\
\text { attention }\end{array}$ & No. & 8,81 & 0,81 & 7,59 & 0,67 & $\begin{array}{c}10.53^{*} \\
*\end{array}$ & signified \\
\hline $\begin{array}{c}\text { precision of } \\
\text { counter-attack }\end{array}$ & No. & $\begin{array}{c}17,7 \\
3\end{array}$ & 0,62 & $\begin{array}{c}16,1 \\
7\end{array}$ & 1,01 & $8.03^{* *}$ & signified \\
\hline \hline
\end{tabular}

The tabular "T" value is at the level of $(0.05)=2.35 \mathrm{l}$. It is clear from Table (3) that there are statistically significant differences on the significance level 0.05 between the distinctive group and non-distinctive group, in favor of the distinctive group, indicating the validity of the variables under study. 


\section{Stability:}

Table (4) The correlation coefficient between the first and second application in the concentration of attention and precision of counter-attack (under study). $\mathrm{N}=(4)$

\begin{tabular}{|c|c|c|c|c|c|c|c|}
\hline \multirow[t]{2}{*}{ measurements } & \multirow{2}{*}{$\begin{array}{c}\text { Measurement } \\
\text { unit }\end{array}$} & \multicolumn{2}{|c|}{$\begin{array}{c}\text { First } \\
\text { application }\end{array}$} & \multicolumn{2}{|c|}{$\begin{array}{c}\text { Second } \\
\text { application }\end{array}$} & \multirow[t]{2}{*}{ T value } & \multirow[t]{2}{*}{ Significance level } \\
\hline & & $\mathbf{S}$ & $\mathbf{A} \pm$ & $\mathbf{S}$ & $\mathbf{A} \pm$ & & \\
\hline $\begin{array}{l}\text { concentration } \\
\text { of attention }\end{array}$ & No. & 7,59 &., 55 & 7,59 & 60 & $0.99 * *$ & signified \\
\hline $\begin{array}{c}\text { precision of } \\
\text { counter-attack }\end{array}$ & No. & 16,17 & 1,01 & 16,17 & 1,09 & $0.98 * *$ & signified \\
\hline
\end{tabular}

${ }^{*}$ Tabular value of $\mathbf{R}$ at $(0.05)=0.900$

Table (4) shows that correlation coefficients between the first and second applications are statistically significant at $(0.05)$ which indicating the stability of concentration of attention and the precision of the counter attack.

After conducting the scientific transactions, the researcher has conducted homogeneity between the research variables and Table (5) shows this.

Table (5) Arithmetic average, standard deviation, and torsion coefficient for the research sample in the research variables (Concentration of attention - precision of counter-attack) $n=8$

\begin{tabular}{c|c|c|c|c}
\hline \hline Rariables & $\begin{array}{c}\text { Measure } \\
\text { ment } \\
\text { unit }\end{array}$ & $\begin{array}{c}\text { Arithmetic } \\
\text { average }\end{array}$ & $\begin{array}{c}\text { Standard } \\
\text { deviation }\end{array}$ & $\begin{array}{c}\text { Torsion } \\
\text { coefficien } \\
\mathbf{t}\end{array}$ \\
\hline Concentration of attention & No. & 10,21 &., 64 & Signified \\
\hline $\begin{array}{c}\text { precision of counter- } \\
\text { attack }\end{array}$ & No. & 18,25 & 1,27 & Signified \\
\hline
\end{tabular}

Table (5) shows that the values of the torsion coefficients in the variables under study have limited to (回3).

This indicates that the distributions are closer to moderation in each of the variables (concentration of attention and precision of counter-attack in the research sample) which indicating the homogeneity of the sample.

\section{* Exploratory study:}

The researcher has adopted in the methods of implementing the proposed training program to improve and develop the concentration of attention and the precision of the counter attack on the results of the exploratory study conducted in the period from 2/3/2017 to $16 / 3 / 2017$ on a sample of (8) boxers representing the original community of the research and from outside the basic research sample. 


\section{*The aim of the exploratory study:}

-Knowing the suitability and validity of the places chosen to conduct and perform the research.

-Knowing the suitability and validity of the instruments and devices used in the measurement.

-Knowing the suitability of the visual vision training for the research sample will be used in the proposed training program.

-Knowing the suitable time to apply the program.

-Defining the assistants how conducting the measurement process "concentration of attention - and the precision of counter-attack for the boxers. (Under the supervision of the researcher).

-Knowing the time that each boxer will take during the measurement process "concentration of attention - and precision counter attack.

-Conducting scientific coefficient to determine the validity and stability of the test of attention concentration and the precision of the counter attack under study.

\section{* Results of the exploratory study:}

The researcher has reached the following results:

-Create the appropriate conditions for the application of the training program in order to get the best results.

-Efficiency and experience of the assistants and their precision in measuring and recording results.

-The extent of the appropriateness of the proposed visual vision trainings for the sample under study.

-The extent of the appropriateness of tools and equipment and proposed training program for the sample under study.

-The extent of the appropriateness of the time for the implementation of the training modules for the sample under study.

-The extent of the appropriateness of the time for the implementation of the attention concentration test and the test of the precision counter attack under study.

-The extent of the appropriateness of the scientific transactions used in the variables under study.

\section{Research steps:}

The researcher has implemented the proposed training program (on the basic sample of the research) as follows:

A) Conducting pre-measurements:

The researcher has conducted the pre-measurements of the variables under study on Thursday, 17/3/2017, which included measuring:

1 -Concentration of attention in the research sample. Attachment (4) 
2-The precision of the counter attack in the research sample. Attachment (5)

\section{B. Application of the proposed training program:}

The researcher has applied the proposed training program from 19/3/2017 to $11 / 5 / 2017$ (for eight weeks, three training units per week) during the preparation period in the college boxing hall.

* General framework of the proposed training program:

\section{Steps of the proposed training program preparation:}

The researcher has put visual vision trainings for boxing players in the 19-20 age groups through:

-Reference survey of Arab and foreign references, which deal with the basics of visual vision training.

-Review the researches and studies that deal with the trainings of the visual vision.

\section{Aims of the proposed training program:}

The proposed training program using visual vision training aims to:

1-Improve and develop the concentration of attention in the research sample.

2-Improve and develop the precision of the counter attack in the research sample Foundations of putting the proposed training program.

The researcher has conducted a survey of several scientific sources, as well as special studies that include visual exercises and a set of exercises has been limited and designed, and then the researcher has put the selected exercises in the poll form of experts, which numbered (12) Attachment (1)

Through this form the researcher has concluded a group of visual exercises according to the opinions of experts. Attachment (7)

\section{Foundations of visual trainings design:}

The researcher has adopted on the following bases to design the visual exercises:

1-Taking into account the objective of visual training.

2-The suitability of the program for the age for the sample under study.

3-Availability of security and safety factors.

4-Taking into account the individual differences between boxers.

5-Provide technical capabilities and design the tools and visual devices.

6-Flexibility of the implementation and application in proportion to the sample research.

7-Taking into account the principles of eye training: Breathing, Blink, Smile, having fun, commit and believe.

8-Availability the element of suspense and seriousness of the proposed exercises. 
9-Consider the similarity of the form of performance of the proposed exercises with the nature of the specialized performance for the boxers.

10-Taking into account the principle of gradual load from easy to difficult during the application of exercises.

\section{Time division of the program:}

The researcher has used the references, studies and previous researches that dealt with the programs in boxing sport in general and visual training in particular. The researcher has also used the opinions of some experts and specialists in the field of training and boxing that used visual training in the design of training programs. They were (12) experts Attachment (1) and that's in putting the proposed program to achieve the aim of the research and table (6) illustrates this.

\section{Table (6)}

The opinions of the experts in identifying the axes of the proposed training program and percentage for each axis

\begin{tabular}{|c|c|c|c|}
\hline No. & axes & $\begin{array}{c}\text { Summation } \\
\text { of experts } \\
\text { opinions }\end{array}$ & percentage \\
\hline 1 & $\begin{array}{l}\text { The duration of the proposed training } \\
\text { program (2) months }\end{array}$ & 12 & $100 \%$ \\
\hline r & $\begin{array}{c}\text { Number of training units per week (3) } \\
\text { units }\end{array}$ & 11 & $91.67 \%$ \\
\hline r & Training unit time (90) minutes & 12 & $100 \%$ \\
\hline$\Sigma$ & $\begin{array}{l}\text { Visual vision trainings time (30-35) } \\
\text { minutes }\end{array}$ & 10 & $83 ، 3 \%$ \\
\hline 0 & $\begin{array}{c}\text { The method of midterm training (high - } \\
\text { low intensity) }\end{array}$ & 9 & $75 \%$ \\
\hline 9 & Weekly load cycle (1: 1$)$ & 9 & $75 \%$ \\
\hline$\checkmark$ & Warming time (15) minutes & 9 & $75 \%$ \\
\hline$\wedge$ & Closing time (10) & 10 & $\% 3 ، 83$ \\
\hline
\end{tabular}

Table (6) shows the number of repetitions and the percentage of opinions of the experts about the axes of the proposed training program. The number of repetitions limited between (9) to (12) repetitions, and the researcher satisfied with the percentage of variables between (75\%) and more from opinions. The duration of the proposed training program has been set for (8) weeks starting from Saturday 19/3/2017 and ending on Wednesday 11/5/2017. 


\section{The content of the proposed training program:}

The researcher has designed the proposed training program in accordance with the scientific basis, the reference survey and the opinions of the experts where the program included the following axes:

Program duration $=2$ months. - Number of weeks $=8$ weeks

Number of training units per week $=3$ units per week

Total number of training units $=3 \times 8=24$ training unit

Training unit time $=90$ minutes

Training unit time per week $=3 \times 90=270$ minutes per week

Total time of training units during the training period $=3$ units $\times 90 \times 8$ weeks $=$ 2160 minutes $=36$ hours

\section{Preparation periods for visual vision trainings:}

Duration of the program: 8 weeks in the preparation period (general preparation, special preparation, preparation for competition)

\section{*General preparation:}

-This period represented the weeks (2.1) by (3) units, the unit time (90) minutes.

Total training unit time in the general preparation

General preparation period $=2 \times 3 \times 90=540$ minutes $\div 60$ minutes $=9$ hours *Special preparation:

-This period represented the weeks $(6,5,4,3)$ by 3 units, unit time is $(90)$ minutes.

Total training unit time in the preparation period for competition.

Pre-competition period $=2 \times 3 \times 90=540$ minutes 60 minutes $=9$ hours Total time during training units during the preparation period.

\begin{tabular}{|c|c|c|c|}
\hline \hline Stage & $\begin{array}{c}\text { General } \\
\text { preparation }\end{array}$ & $\begin{array}{c}\text { Specific } \\
\text { preparation }\end{array}$ & $\begin{array}{c}\text { Pre-match } \\
\text { period }\end{array}$ \\
\hline
\end{tabular}

Preparation period $=540+1080+540=2160$ minutes 60 minutes $=36$ hours

Time distribution of proposed program variables:

-Warm-up 15 minutes $\times 24$ Training units $=360$ minutes $16.7 \% \rightarrow$

-Closing (calm) 10 minutes $\times 24$ Training Units $=240 \quad 11.1 \%$

-Visual vision training $30 \times 15$ units +35 minutes $\times 9$ units $=765$ minutes

$35.42 \%$

- General physical preparation: 15 minutes $\times 15$ units $=225$ minutes $\quad 10.42 \%$

-The skill preparation 20 minutes $\times 15$ units +30 minutes $\times 9$ units $=570-$ minutes $26.39 \%$

-so the total program time $=360$ minutes +240 minutes +765 minutes +225 minutes +570 minutes $=2160$ minutes 
Table (7)

Time and relative distribution of warm-up and preparation

\begin{tabular}{|c|c|c|c|c|c|c|c|c|c|c|}
\hline \multirow{2}{*}{\multicolumn{3}{|c|}{$\begin{array}{c}\text { Pre-matches period } \\
r+17 / 0 / 11: r\end{array}$}} & \multicolumn{4}{|c|}{ Specific preparation } & \multicolumn{2}{|c|}{$\begin{array}{c}\text { General } \\
\text { preparation }\end{array}$} & \multirow{2}{*}{\multicolumn{2}{|c|}{$\begin{array}{c}\text { stage } \\
\text { Time period }\end{array}$}} \\
\hline & & & \multicolumn{4}{|c|}{$r+1 Y / \& / r=r$} & \multicolumn{2}{|c|}{$r+17 / r / r+z 19$} & & \\
\hline $\begin{array}{l}\text { summ } \\
\text { ation }\end{array}$ & $\begin{array}{l}\text { eigh } \\
\text { th }\end{array}$ & $\begin{array}{l}\text { seve } \\
\text { nth }\end{array}$ & sixth & fifth & $\begin{array}{c}\text { fourt } \\
\text { h }\end{array}$ & third & second & first & & Weeks \\
\hline$r$ & & & & & & & & & Max. & \multirow{3}{*}{ 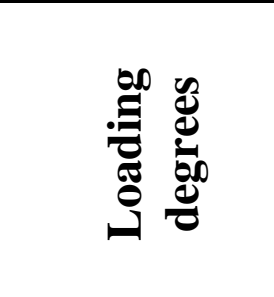 } \\
\hline$r$ & & & & - & & & & & high & \\
\hline$r$ & & & & & & $\bullet$ & & $\bullet$ & Med. & \\
\hline$\% 1 \ldots$ & irso & IrGo & irso & $1 r_{60}$ & Ir6o & Ir6o & Ir6o & Ir6o & $\%$ & \multirow{2}{*}{$\begin{array}{c}\text { Warming-up } \\
\text { by minutes }\end{array}$} \\
\hline $360 \mathrm{~m}$ & 45 & 45 & 45 & 45 & 45 & 45 & 45 & 45 & $\mathbf{m}$ & \\
\hline$\% 1 \ldots$ & - & - & - & 20 & 20 & 20 & 20 & 20 & $\%$ & \multirow{2}{*}{$\begin{array}{c}\text { General } \\
\text { physical } \\
\text { preparation }\end{array}$} \\
\hline rrom & - & - & - & 45 & 45 & 45 & 45 & 45 & $\mathbf{m}$ & \\
\hline$\% 1 \ldots$ & Iror & Iror & IrGr & 11 11 & 11،A & 11،A & 11،A & $116 A$ & $\%$ & \multirow{2}{*}{$\begin{array}{c}\text { Visual vision } \\
\text { trainings }\end{array}$} \\
\hline riom & 1.0 & 1.0 & 1.0 & 9. & 9. & a. & 9. & 9. & $\mathbf{m}$ & \\
\hline$\% 1 \ldots$ & 1061 & 1061 & 1061 & 1.60 & 1.60 & 1.60 & 1.60 & 1.60 & $\%$ & \multirow{2}{*}{$\begin{array}{c}\text { Skillful } \\
\text { preparation }\end{array}$} \\
\hline or.m & $9 \cdot m$ & $90 \mathrm{~m}$ & $90 \mathrm{~m}$ & $60 \mathrm{~m}$ & $60 \mathrm{~m}$ & $60 \mathrm{~m}$ & $60 \mathrm{~m}$ & $60 \mathrm{~m}$ & $\mathbf{m}$ & \\
\hline$\% 1 \ldots$ & ir,o & ir,o & Ir,o & Ir,o & ir,o & irco & irco & Ir,o & $\%$ & \multirow{2}{*}{$\begin{array}{c}\text { Closing time } \\
\text { part }\end{array}$} \\
\hline $240 \mathrm{~m}$ & r. & r. & r. & r. & $r \cdot$ & r. & $r_{\bullet}$ & $r_{\bullet}$ & $\mathbf{m}$ & \\
\hline $2160 \mathrm{~m}$ & $\begin{array}{c}270 \\
\text { m }\end{array}$ & $\begin{array}{c}270 \\
\text { m }\end{array}$ & $270 \mathrm{~m}$ & $270 \mathrm{~m}$ & $270 m$ & $270 \mathrm{~m}$ & $270 \mathrm{~m}$ & $270 \mathrm{~m}$ & \multicolumn{2}{|c|}{ Total by minutes } \\
\hline
\end{tabular}

(General and skillful preparation) and visual vision trainings and closing through the stages of the proposed training program on the different loading degrees

Table (7) shows the distribution of the actual and relative time of various preparations through weeks and stages of the proposed training program on the different loading degrees

C - Conducting the post measurements:

All measurements should be taken as measured in the pre measurement. The researcher has conducted the post measurements of the variables in question, on Thursday, 12/5/2016, which included measuring: 
1-Concentration of attention in the research sample. Attachment(4)

2-The precision of the counter attack in the research sample. Attachment(5)

\section{Used statistical processors :}

The researcher has used the following statistical method:

Arithmetic average. - Mediator. - Standard deviation. - Torsion coefficient.

(T Test) for statistical differences significance - coefficient of improvement

rates for averages.

*Presentation and discussion of the results:

(First): View results

-View the results of the first hypothesis:

*Concentration of attention "under study"z

Table (8)

The significance of the differences between the mean scores and the improvement rate in the pre and post measurements

Concentration of attention in the research sample $n=(8)$

The tabular value of $(t)$ at the level $(0,05)=1.89$

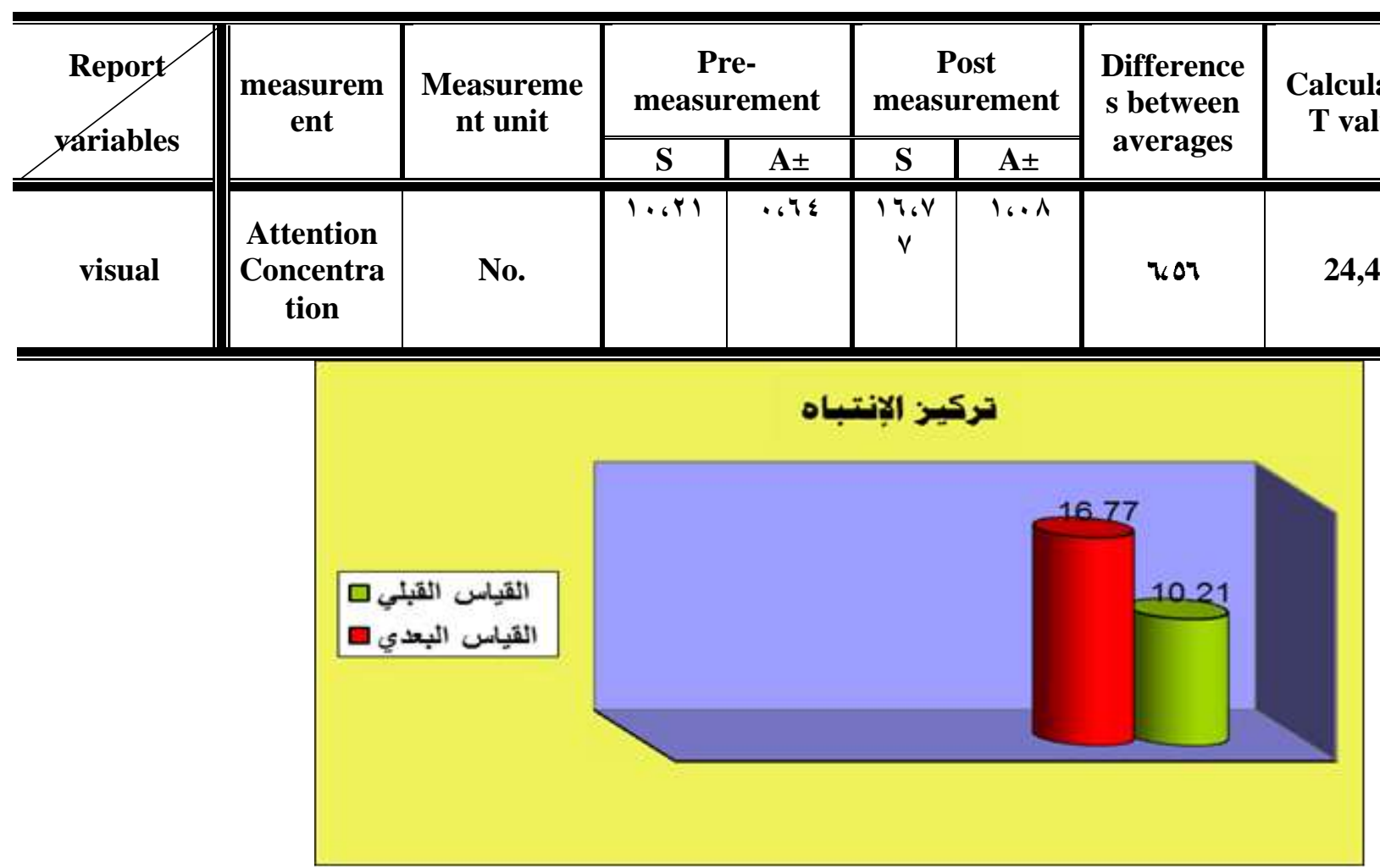

Figure 1

تركيز الانتباه Attention Concentration post measurementimeasurement

Table (8) and Figure (1) show that there are statistically significant differences between the averages scores of the pre and post measurements in the concentration of attention "under study" in the research sample in favor of the 
post measurement, where the calculated value of $(t)$ was $(24,44)$ and the improvement rate was $64.25 \%$ which indicating that the calculated value of $(\mathrm{t})$ is greater than the tabular value of $t$ at $(0,05)$ and the improvement rate was in favor of the post-measurement in sample of the research.

-Presentation of the second hypothesis results :

* Counter-attack precision:

The tabular value of $t$ at the level $(0,05)=1.89$

\begin{tabular}{|c|c|c|c|c|c|c|c|c|c|}
\hline \multirow{2}{*}{ Repopt } & \multirow{2}{*}{$\begin{array}{c}\text { measure } \\
\text { ment }\end{array}$} & \multirow{2}{*}{$\begin{array}{c}\text { Measure } \\
\text { ment } \\
\text { unit }\end{array}$} & \multicolumn{2}{|c|}{$\begin{array}{c}\text { Pre- } \\
\text { measureme } \\
\text { nt }\end{array}$} & \multicolumn{2}{|c|}{$\begin{array}{c}\text { Post } \\
\text { measureme } \\
\text { nt } \\
\end{array}$} & \multirow{2}{*}{$\begin{array}{c}\text { Differen } \\
\text { ces } \\
\text { between } \\
\text { average } \\
\text { s }\end{array}$} & \multirow{2}{*}{$\begin{array}{c}\text { Calculat } \\
\text { ed T } \\
\text { value }\end{array}$} & \multirow{2}{*}{$\begin{array}{l}\text { Improvem } \\
\text { ent rate }\end{array}$} \\
\hline & & & $\mathbf{S}$ & $\mathbf{A} \pm$ & $\mathbf{S}$ & $\mathbf{A} \pm$ & & & \\
\hline $\begin{array}{l}\text { Skillful } \\
\text { physical }\end{array}$ & $\begin{array}{c}\text { Counter } \\
\text {-attack } \\
\text { precisio } \\
\text { n }\end{array}$ & No. & $\begin{array}{c}11_{6} Y \\
0\end{array}$ & $1, Y \mathrm{~V}$ & $\begin{array}{c}r q, 4 \\
7\end{array}$ & $\begin{array}{c}163 \\
0\end{array}$ & $\Lambda_{6} 11$ & $r 1.67$ & $\% \leqslant \varepsilon, \varepsilon r$ \\
\hline
\end{tabular}

Figure 2

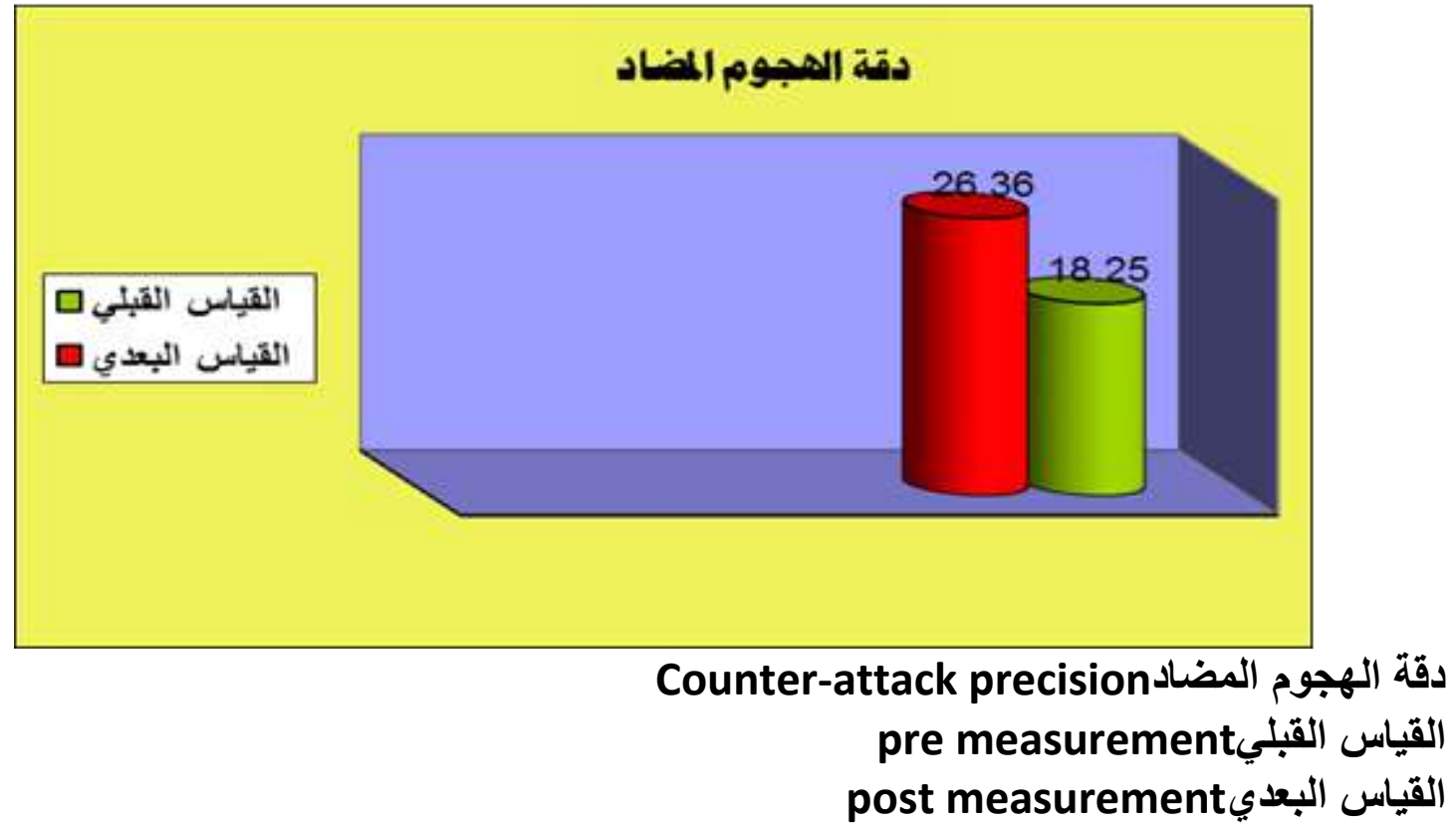

Figure (2) shows the differences between the degrees of the pre and post measurements in the precision of counter-attack among the boxing players -Table (9) and Figure (2) show that there are statistically significant differences between the degrees averages of the pre and post measurements in the precision of the counter-attack in the research sample in favor of the post measurement, where the calculated value of $(t)$ was $(31,76)$ and the improvement rate $(44,43)$ where indicating that the calculated value of $(t)$ is greater than the tabular value of $t$ at $(0,05)$ and the improvement rate in favor of the post-measurement in the research sample. 


\section{(Second) Discussion of results:}

\section{1-Discussing the results of the first hypothesis:}

To investigate the aims of the research by validity of the hypotheses, the researcher has compared the results of degrees averages of the pre and post measurements in the measurements of the visual variable and the "physical skill" variable in favor of the post measurements for the sample under study if found, and to find the significance of the statistical differences between the averages of pre and post measurements using the statistical program " SPSS".

Through this the researcher discussed the results to verify the validity of the first hypothesis, which states that "there are statistically significant differences between the degrees averages of the pre and post measurements in the concentration of attention in favor post measurement".

Table (8) and Figure (1) show that there are statistically significant differences between the degrees averages of the pre and post measurements at the level of 0.05 for the visual variable in favor of the post measurement.

Where the calculated value of $\mathrm{T}$ in the concentration of attention was (24.44) and the improvement rate (64.25\%). This indicates that the calculated value of $\mathrm{T}$ is greater than the tabular value of $\mathrm{T}$ at 0.05 and the percentage of change was in favor of post measurement among boxers (the research sample).

The researcher has attributed the reason for these differences that the use of visual training exercises had a positive impact on the development of counterattack for boxers. This agreed with the study of Huda Hassan (2008) 16, Hatem Fathallah (2008), 6 Nahla Jamal (2008) (15) where the study indicates that visual training helps to develop both fixed and moving visual precision, and attention concentration.

In addition, the results of the study of Majid Mustafa Ahmed Ismail, Abdel Mohsen Zakaria Ahmed (2006) (10), which state that the process of education and training using visual vision training has a positive effect in the level of skilled performance advancing and also the visual capabilities play an important role in the performance efficiency and that capacity can be developed through the well-designed visual training programs.

As Usama Rateb (2000), Brain Ariel (2004) and Isabel Walker (2001), have referred that visual training leads to eye vision improvement and depth increasing of the aim achievement and considered from the most important modern trainings which increase the responding to different stimuli and used for small goals during the game performance. The researcher explains this that the visual vision training of the boxers leads to the concentration and nondispersion during the hitting of the offensive punches strongly, quickly and accurately when the competitor allows this, which leads to control and win the game which shown in figure( ). 
This is corroborated by the study of Poulter et al. (2005) (22), Thomas.et al (2005) (23), Hatem Fathallah (2011) (6) that the visual vision trainings leads to the increasing the concentration of players and lack of dispersion and the ability to achieve the performance of the movement during the matches leading to a positive result. Based on the results of Table (8) and Figure (1), the researcher has concluded that the use of visual exercises within the program led to improved attention concentration. These results have achieved the validity of the first hypothesis of the research which states that. "There are statistically significant differences between the degrees averages of the pre and post measurements in the concentration of attention in favor of post measurement".

\section{2-Discussing the results of the second hypothesis:}

In light of the results of the statistical analysis, and within the limits of the measurements used and through the research aims, the researcher has discussed the results to verify the validity of the second hypothesis, which states that "there are statistically significant differences between the degrees averages of the pre and post measurements in the precision of counter-attack in favor of post measurement".

Table (9) and Figure (2) show that there are statistically significant differences between the degrees averages of the pre and post measurements of the "skillful physical" variable in favor of post measurement. Where the calculated value of $(T)$ in the precision of the counter attack (31.76) and the improvement rate $(44.43 \%)$ which indicating that the calculated value of $(t)$ is greater than the tabular value of $(t)$ at $(0.05)$ and the improvement rate in favor of the post measurement for the boxers "sample research".

The researcher has attributed the reason for these differences that the use of qualitative visual vision trainings to improve the precision of counter-attack has had a positive impact on the development of the skill of the boxers during the game. This is also consistent with the study of "Huda Hassan" (2008) (16), "Hatem Fathallah" (2011) (6), "Nahla Jamal" (2014) (15) where have referred that the visual trainings help to develop both of the fixed and moving visual precision, and the depth perception and the rounding vision, which will be positive for the players during the matches.

This is confirmed by the results of the study of Majid Mustafa Ahmed Ismail, and Abdul Mohsen Zakaria Ahmed (2006) (10) that the training of visual vision has a positive effect in advancing the level of skilled performance of the players, and the visual capacity plays an important role in the effectiveness of the movement performance and that this capacity can be developed through the design of visual training programs well. 
The researcher believes that the training program using the visual vision has had an effective impact on the precision of counter-attack for boxers, which returns positively on results of the matches.

That is what the study of "Abernethy and Wood" (2002), 17 "Elizabeth S3.Bresson" (2003), 19, Thomas.et al (2005) (23)Jihan Fouad, Eman Abddallah(5)(2005), Nadia Alsawai, Zeinb Hathot(2008)(14) (2006)," Huda Hassan (2008), 16 ", Majid Mustafa, 'Abd al-Mohsen Zakaria (2006)(10) Hatem Fathallah (2011), (6), and "Nahla Gamal" (2014) (15), refer to that the use of visual exercises have a positive impact in improving the concentration of attention, precision and speed of performance of players. Ashraf Mustafa's study (2008) (3) confirms that the importance of using qualitative training to improve the precision of counter attack for boxers.

Based on the results of Table (9) and Figure (2), the researcher has concluded that the use of visual vision trainings within the program led to the improvement of precision of the counter attack. These results validate the second hypothesis of the research, which states that. "There are statistically significant differences between the degrees averages of the pre and post measurements in the precision of counter-attack among the boxing players in favor of post measurement.

Conclusions and Recommendations:

\section{Conclusions:}

-The proposed qualitative visual vision exercises have a positive effect on improving the concentration of attention and non-dispersion of boxing players through hitting punches.

-The proposed qualitative visual vision exercises have a positive effect on improving the precision of the counter attack represented in (precision of distance perception, precision and speed of punching after avoiding competitor punch) for boxing players.

- The rates of improvement of the post measurement are more that of pre measurement through the application of the proposed qualitative visual vision exercises in the concentration of attention and precision of counter-attack for boxers, which returned positively to the results of matches.

-There is a positive correlation relationship between the concentration of attention and the precision of counter-attack in boxing players.

\section{Second: Recommendations:}

-The need for using the qualitative visual vision trainings of boxing players because they have positive impact on the improvement of concentration of attention and non-dispersion during hitting the punches. 
-The need for using the qualitative visual vision trainings of boxing players because they have positive impact on the improvement of precision of the counter-attack during matches.

-Paying attention for putting training programs using qualitative visual vision trainings in accordance with the scientific foundations of different age groups of boxing players.

-Providing the necessary and sufficient tools and equipment for visual vision trainings of quality in proportion to modernity, security and safety requirements.

-The need for design qualitative visual tests for some of the basic skills in boxing.

-Interesting in conducting other similar researches in order to benefit from in the training of boxers.

\section{References:}

\section{First: Arabic References:}

1-Osama Kamel Rateb: Sports Psychology (Concepts - Applications), 2nd print, Dar Al-Fikr Al Arabi, 1997.

2-Osama Kamel Rateb: Training of Psychological Skills Applications in the Field of Sports), Dar Al-Fikr Al Arabi, 2000.

3-Ashraf Mustafa Ahmed: "The Impact of Qualitative Exercises Program for the Development of Sensory - Kinetic

Perception on some aspects of Attention and Precisio of Hitting the Offensive Counter-attacks for New Boxers,"Published Research, Assiut Journal of Sports Education Sciences and Arts. No. 27, Part II, 2008

4-Ismail Hamed Osman: "Law and Arbitration by the Computer in Boxing, Dar Saada For Printing, Cairo, 1997.

5-Jihan Mohammed Fouad, and Iman Abdullah Zaid: The Effectiveness of Visual Training on some Skillful Variables and Visual Abilities in Volleyball, Published Research, Journal of Comprehensive Education Research, Vol. II, No2 Faculty of Physical Education for Girls, Zagazig University, 2005.

6-Hatem Fathallah AlHafni: Effect of Training Program using Visual Trainings on the Presicion and the Speed of Performance of some Offensive and Defensive Skills in Fencing, Unpublished PhD, Faculty of Physical Education, Assiut University, 2011.

7-Sherif Mohammed al-Awadi and Omar Muhammad Labib: The Bases of the Kumite Attack (Karate Series and the Kumite Set), Minia University, 2004.

8-Abdel Rahman Abdel-Azim Saif: "Sports Training for Boxers",1st Printing, Alwafaa For Printing \& Publishing, Alexandria, 2011.

9-Abdel Fattah Fathi Khder: "the Reference in Boxing", the Facility of Knowledge, Alexandria,1996. 
10-Majed Mustafa Ahmed Ismail, Abdel Mohsen Zakaria Ahmed: Effect of Vision Trainings on some Visual Abilities and Skill Level in Football, Published Research, Assiut Journal of Sports Education Sciences and Arts No. 23, Part IV, 2006

11-Mohamed Sobhi Hassanein: Measurement and Evaluation in Physical Education and Sports, Part I, 4th printing, Dar Al-Fikr Al-Arabi, Cairo, 2001.

12-Mohamed Abdel Aziz Salama: Some of the Effects of the Environment of Learning and Performance in the Field of Sports, Scientific Article, Faculty of Physical Education for Boys, Alexandria University, 2004.

13-Mufti Ibrahim Hammad: "The Comprehensive Reference in Sports Training (Practical Applications)", Dar Al kttab Alhadeeth, Cairo, 2010.

14-Nadia Hassan El-Sawy, Zeinab Ali Hathout: Effectiveness of Visual Trainings on Cognitive Skills, Visual Abilities and Improvement of the Offensive Skillful Level in Handball, Published Research, Journal of the Third International Scientific Conference, Faculty of Physical Education for Girls, Zagazig University, 2008.

15-Nahla Jamal Ali: "The Impact of Training Program using Visual Exercises on some Cognitive Levels and Level of Shooting Precision for Handball Beginners" Unpublished Master Thesis, , Faculty of Physical Education, Assiut University, 2014.

16-Huda Hassan Saber Yousef: Effect of using Visual Exercises on Improving the Precision of Scoring Points and the Concentration of Attention on Female Kumite Players, Unpublished Master Thesis, Faculty of Physical Education for Girls, Zagazig University, 2008.

\section{Second: Foreign References:}

17-Abernethy B.woodJM: Do generalized visual Training programmers For sport really work An experimental invest Tigation, University of queen sland Journal sport Sci, mat, (19), (3), 2002.

18- Brain Ariel : Sports Vision Training: An Expert Guide improving performance by training the eyes, Human perception and Human perception, 2004.

19-Elizabeth s.Bressa: Effects of visual skills training vision coaching and sport vision dynamics on the performance of sport skill, African Journal for physical, Health Education , Recreation and Dance, vol.9, No, 1, 2003.

20-Isabel Walker: Why Visual Training Programmers for Sport sci, Mar 19 (3) p 20- 22, 200

21-Littlefield \& Broderick: sports vision(Giving you the Visual Advantage)28Maine Street, Brunswick, MA 04011, 1998. 
22-Poultera, et al : The evict of learning condition on perceptual anticipation, awareness, and visual search . University of Hong Kong, Human , No, 1, 2005.

23-Thomas,L,et ,al :Visual evoked potentials reaction and egedominance in cricketers, University of the wit water and Johannesburg ,south Africa ,Journal of sports medicine and physical ,2005.

\section{Third: International Information Network:}

24-http://www.Iraqacad.org/hile/amro.htm.

25-http://www. Pponline.co.uk/necyc/0622.html.

26-http://www. Sporteyes.com/vtp.htm.

27-http:/www. Wellcoaches.com /index.php. 